\title{
Self-Confidence of Students with Disabilities in College Level Linguistic Class
}

\author{
Elena Melnikova* \\ Professional English Chair, Kuban State University (KubSU), Krasnodar city, Russia
}

\begin{abstract}
The goal of this study is to determine the difference of linguistic literacy and selfconfidence of students with disabilities in an English class. An enhanced understanding of how students' self-confidence influences benefits of educational linguistic practice. In this article the concepts of linguistic literacy and the storytelling as one of the methods are examined and discussed. In linguistic field, self-confidence was predicted by various factors: current selfconfidence of students with disabilities was most strongly predicted by received praise, current grades, and interest in linguistics. The number of under-confident students was reported consistently higher than the number of confident students, highlighting that under-confidence may ultimately be motivationally detrimental. The data for this study were collected through linguistic literacy test and a questionnaire at the English class which was distributed through a randomized sampling method. Students with disabilities who have had linguistic experience have a higher level of self-confidence in linguistic literacy than students who have not attended the class. This study provides means to improve self-confidence of students with disabilities' and at the same time improves linguistic literacy which allow them to achieve higher personal, career goals and prosperous future.
\end{abstract}

\section{Introduction}

Self-confidence of students with disabilities in linguistic class has undoubtedly practical relevance to their successful college level education: self-confidence of students with disabilities was always associated with their educational motivation and willingness to achieve the linguistic literacy [1]. The current study is focused on students with mild disabilities for they are able to study in linguistic class. Nowadays Public Laws continue to emphasize placing students with disabilities into general education setting in Russia. The inclusion is seen as a social process of communication in linguistic class. To capture and put words that are offered by college level practice and the students with disabilities' participation, a conceptual framework was done in order to describe this successful study of students with disabilities in an English class.

\subsection{Theoretical and Practical Reasons}

So during the past ten years, in Russian research there has been an increase in study of students in inclusion education to help the college level teachers understand what is needed to make inclusion at all levels and spheres more successful. Even vital feeling of belonging of students with disabilities is rather critical and crucial to students' motivation to study and self-confidence [2, 3]. The term «self-confidence» in psychology comprises «self-efficacy» that means specific beliefs to particular academic subjects $[2,4]$, and «self-concept» that means students with disabilities' evaluative beliefs about their future capacities, such as their confidence in being able to gain a particular examination grade or to successfully accomplish a particular type of exercise. When they are self-confident, students with disabilities positively interpret their own linguistic background, including their own personal linguistic experiences, which form and influence their positive beliefs about their own abilities; these beliefs then form their expectations of success; these beliefs guide students' actions and choices. Such factors are assumed to influence one another. A commitment to quality linguistic education entails a belief that each inclusion student can learn and succeed, that linguistic diversity enriches them, that students with disabilities can learn better through foreign language activity and communicative study involvement, and that promotes self-confidence and effective learning results [5]. The association between education and literacy itself is well researched and well established [6] for literacy is an integral part of college education. Linguistic literacy is a rather ambiguous concept that has become a remarkable point of today's studies [1] in academic and public sciences. College education surely influences skills and knowledge of all students with disabilities as well as provides development of multiple literacy that also comprises linguistic literacy [7, 8]. Linguistic literacy is not well-defined as a distinctive concept, but within the framework of our research it is viewed mainly as a broad comprehension, communication skill that

Corresponding author: arthelen@mail.ru 
determine students with disabilities' motivation for reading, writing, speaking ability of individuals to gain intercultural exchange, to successfully use linguistic information in ways that maintain a positive work attitude [9].

Some teachers of linguistics raise fundamental questions regarding the most effective ways to provide students with disabilities with high quality linguistic literacy that meets their individual educational needs and improves their self-confidence and social well-being in the context of college level study [6]. Linguistic literacy may be conceptualized as a possible pathway by which the link between linguistic education and self-confidence can be researched, comprehended and interpreted [5]. Moreover a large body of methodological and psychological research itself establishes a strong, positive correlation between successful literacy of students with disabilities and self-confidence [8]. The link between education and self-confidence of students with disabilities has diverse interpretations [3, 8, 10], therefore this correlation is defined as a versatile one and mechanisms in this case underlying "education means self-confidence" association have neither been fully worked out nor brought to fruition [6]. Consequently, understanding the ways by which linguistic literacy in a linguistic class affects individual inclusion student selfconfidence and students with disabilities' educational outcomes can be a challenging and not an easy goal to achieve.

There is evidence that low linguistic literacy of students with disabilities is associated with underconfidence. Under-confidence results in poor use of linguistic skills and limited communication skills.

As linguistic literacy affects any forms of selfconfidence and social behaviour, there is also need to develop, improve and promote linguistic literacy among students with disabilities. Self-confidence and linguistic literacy of students with disabilities of college level are closely interconnected. Under-confidence has mainly been shown to be motivationally degrading [8], and it has negative educational implications; under-confident students with disabilities may not select communicative fields, topics, phrases etc. ; that they might succeed in and enjoy $[1,5]$. However, the reasons that lead students with disabilities potentially to under-confidence and their influences of it remain vague. An enhanced understanding of the issue could lead to practical benefits: students with disabilities' under-confidence could potentially be amended via teachers or co-students, the higher their progress and linguistic literacy in a linguistic class the higher their self-confidence. When they study English and linguistics in college step by step, it shapes students with disabilities' self-confidence in general. Studies of students with disabilities have revealed high accuracy, persistence, mastering goals in linguistic classes. However at the begining of their study, under-confidence of students with disabilities was rather low.

We find one of effective and powerful methods at an English class to transmit useful linguistic knowledge in a contextual manner that has meaning to others is storytelling method [7]. This can best be presented as worked information. A storytelling method is similar to every inclusive student to share his/her success in the programme. Through storytelling and collaboration, college teachers can create a team of learning in a nonrisky manner, where everyone who can affect inclusive student outcomes is welcomed to be both a student and a teacher. In order to build an inclusive linguistic team, all students need to feel as though they belong and have a voice. The most important requirement for the storytelling method to work is to maintain opportunities for interested parties in the inclusive communicative process to talk and share. It also is vital that student in a class has the space and permission to share not only what is positive and enjoyable related to inclusion, but also what is negative and hard. Teachers in an English class with students with disabilities must provide safe learning environment. Some students with disabilities struggle at the beginning, some enjoy, which is normal in a diverse college education. However, because a team and cultural values and standards concerning what is vital to share vary greatly, it is also essential that everyone who shares is reverential of individual differences of every student in an English class. Safe spaces cannot be appointed; they must be created teamwise. Everyone who participates in the storytelling method must have obviousness that their sharing will be positively received.

Formal and informal ways to create ways to share linguistic stories of inclusion are diverse. Informal ways are usually made on the spot by students when they meet in some way in the college hall or college cafe, library room and so on. Formal methods include scheduled college classes at a comfortable location. The group must be of a reasonable size, up to 14 members, so all members can participate in a linguistic conversation. The group talk can begin with and be simplified through the use of a breaking the ice issue, a quiestion or news. Example: "Who would like to share something exciting or upsetting that had recently happened in your life? What's going on?" it is a prompt to start the discussion in a class and all students say something that is new or positive about inclusion in college education. As the linguistic team is built, the students with disabilities will trust each other more and share more their meaningful ideas. Another formal activity for a linguistic teacher is to create an electronic students' linguistic quiz chart. This chart is needed for one inclusive student to share an issue or a story for another students who have already had the same linguistic experience or issue to give his peices of advice. They use chart to prompt linguistic discussions and record possible solutions to the issues that are shared by most of the students with disabilities participating. Important topics for storytelling with students with disabilities in English class include the following:

- How study of the English language helps me and the improvement I need in an English class.

- How to meet the individual goals of all students with disabilities conserning linguistic literacy.

- Linguistic team shared knowledge responsibility and study. 
- Situations when differences in comunication can become the basis for oppression. The goal of storytelling method is to acknowledge the value of human beings diversity and to create team dialogue that rises evaluation of his/her self-confidence and reflects on friendly solutions and every student with disabilities of the linguistic team can feel a sense of connection and belonging to college community.

\section{Methods}

The goal of this theoretical research is to highlight the interdependence of self-confidence and linguistic literacy and to identify linguistic literacy challenges for college level education. The on-going course is an ongoing study to understand a phenomenon through interpersonal methods [4, 11]. In this study, the phenomenon of self-confidence of students with disabilities in linguistic class is to be understood, hence the methods used are interpersonal. Interviews, discussions and lessons with teachers were observed and recorded during the first year of the course. 28 interviews used in an empirical example, 15 observations at lessons and 2 groups of interviews were made from 2 English classes.

A semi structured approach was used in the interviews [7, 8, 9, 12]. Some English class teachers were invited to elaborate on their view on selfconfidence of students with disabilities. In their opinion under-confidence is the key factor in poor participation in linguistic class and poor participation rate. The analysis was made using data and empirical material. This quantitative research reviews self-confidence of students with disabilities within linguistic literacy classification according to three levels: under-confidence (score 60\%), optimal self-confidence (score 30\%), high self-confidence (score 10\%). The following for linguistic literacy classification assessment criteria can be used: 1) External - active elements as students with disabilities and teachers are concerned, occasion, social setting, communicative function of the pieces of language, etc. 2) Internal - recurrence of language models within the pieces of language, etc. are concerned.

\section{Results and discussion}

The meaning and standard deviation of students with disabilities self-confidence on the basis of the linguistic literacy test in an English class result in two semesters before storytelling method and after it had been implied can be found in the following Table 1 .

Table 1 of data processing outcome showed the meaning of linguistic literacy test and self-confidence in first semester (group 1) students with disabilities, underconfidence is the lowest compared to students with disabilities' under-confidence rates in their second semester (group 2). The first semester (group 1) students with disabilities' optimal confidence is medium in comparison with second semester rates (group 2). High self-confidence of the first semester (group 1) students with disabilities is about the same rates in both groups in the second semester (group 2). It is evident that in the second group with students with disabilities where the storytelling method was used there are positive results in the second semester. The linguistic literacy average score was gained according to its assessment criteria of self-confidence in those groups of students with disabilities. Its results are shown in Table 2.

Table 1. Correlation of self-confidence of students with disabilities according to the linguistic literacy growth using storytelling method.

\begin{tabular}{|c|c|c|c|c|}
\hline & \multicolumn{2}{|c|}{ First semester } & \multicolumn{2}{|c|}{ Second semester } \\
\hline \multirow{2}{*}{$\begin{array}{l}\text { under- } \\
\text { confidence }\end{array}$} & $1^{\text {st }}$ group & $\begin{array}{c}2 \mathrm{~d} \\
\text { group }\end{array}$ & $\begin{array}{l}1^{\text {st }} \\
\text { group }\end{array}$ & $2 \mathrm{~d}$ group \\
\hline & $60 \%$ & $50 \%$ & $20 \%$. & $10 \%$ \\
\hline $\begin{array}{l}\text { optimal self- } \\
\text { confidence }\end{array}$ & $30 \%$ & $40 \%$ & $40 \%$ & $50 \%$ \\
\hline $\begin{array}{l}\text { high self- } \\
\text { confidence }\end{array}$ & $10 \%$ & $10 \%$ & $40 \%$ & $40 \%$ \\
\hline
\end{tabular}

Table 2. Linguistic literacy classification assessment rates according to self-confidence criteria in both semesters.

\begin{tabular}{|c|c|c|}
\hline & $\begin{array}{c}\text { External } \\
\text { component }\end{array}$ & $\begin{array}{c}\text { Internal } \\
\text { component }\end{array}$ \\
\hline $1^{\text {st }}$ semester - Group 1 & $60 \%$ & $40 \%$ \\
\hline $1^{\text {st }}$ semester - Group 2 & $65 \%$ & $35 \%$ \\
\hline $2 \mathrm{~d}$ semester - Group 1 & $45 \%$ & $55 \%$ \\
\hline $2 \mathrm{~d}$ semester - Group2 & $55 \%$ & $45 \%$ \\
\hline
\end{tabular}

This indicated that in $1^{\text {st }}$ semester students with disabilities' comprehension in linguistics is still controversial, but in the $2^{\mathrm{d}}$ semester it's more stable. Observing these two criteria or linguistic literacy aspects, we may see that external component is higher than internal one in the first semester. But after the storytelling method had been adopted in the second semester the results of both groups of internal criteria became more or less equal. It means that within the linguistic study process both linguistic literacy aspects are worked out successfully considered well-balanced. The presented research contributes some self-confidence knowledge to general linguistic literacy in education. Under-confident students with disabilities were shown at the beginning to report lower interest in linguistic science when compared to accurately-evaluating students, affirming that under-confidence can be detrimental or limiting within college education. The self-confidence in linguistics class could be predicted by their language interest and utility for college education above the effect of their reported grades.

Students with disabilities with different confidence biases can be inferred to form their beliefs in different ways: different factors with different magnitudes 
predicted self-confidence (self-concept or self-efficacy $[8,10])$ when the students were under-confident. The self-confidence of under-confident students with disabilities could be predicted by their subjectcomparisons, together with other factors, and not by their perceived utility of college education. Under-confident students with disabilities reported lower interest and utility for college education while reporting the same current grades as accurately-evaluating students with disabilities. Under-confident students do not lack ability, usually scored high results on the questionnaire tasks. Since self-confidence, interest, and utility are closely associated with students' subject choices [7, 13], underconfident students may perceive their educational options to be limited: low confidence in their expected grades may mean that profound education is not considered as a potential option. Motivation appears to an internal aspect of self-confidence, and expressions of self-confidence appear to be also expressions of motivation. Self-confidence as reflecting motivation is maybe more clearly seen. Within education, it is contextually-relevant to consider interest and motivation rather than focus only on positive states. Students with disabilities with different self-confidence inclinations were influenced in different ways. Viewing underconfidence may be necessary before assuming that increasing interest in college education can promote higher self-confidence for students with disabilities. It was proved as beneficial to combine some classroom assessment with also asking about their confidence in their answers, and so potentially increase students' selfreflection and also reveal and raise under-confidence. Feedback could be prearranged so that students with disabilities can reflect on their successful experiences, rather than on any other negative feelings. Different reminders may also be useful regarding college education as inclusive: results can be enjoyed by everyone.

\section{Conclusion}

Linguistic learning plays a highly important role for students with disabilities to have the ability to comprehend, communicate, and act in their cultural and behavioral interests. Undoubtedly linguistic literacy as a result of linguistic learning has broad positive results in college level education and is practically useful for selfconfidence of students with disabilities. Learning process and assessment technique used by teachers in English class in their daily determine students with disabilities' success in comprehending and implementing linguistic material received at the lessons [3, 4, 8]. Learning in an English class will bring better results when using an active story telling method. Core linguistic skills have to be taught to students with disabilities so they can use them in their daily life. This research result comports with the research conducted [3, 11], which stated that there is influence between linguistic literacy at college and positive self-confidence in the cognitive aspect.
The concept of linguistic literacy self-confidence of students with disabilities indicates a reciprocal and meaningful association between education, literacy and self-confidence. An impressive progress characterizes the field of linguistic literacy. The concept of linguistic literacy has occurred and presents itself as a complicated and ambiguous theoretical issue that challenges traditional college education and its theoretical and methodological principles. Diversity and comprehensiveness of linguistic literacy concept can be perceived as a challenging aspect for college education. Linguistic literacy is not any more an individual trait. It's not simply linguistic knowledge or profound knowledge in an English class. Linguistic literacy gains more broad and comprehensive terms and conceptualizations. Multilayered models of linguistic literacy require more complex college education. Functional linguistic literacy predominantly focuses on the communication of language-related information, interactive linguistic literacy is oriented towards development of personal skills that are required in college environment, and critical linguistic literacy focuses particularly on personal and college groups' capacity building $[6,13$, 14]. Besides the functional aspects of linguistic literacy there should be also information and awareness of the social criterions of linguistic included into college education policies. College education should encourage critical thinking, motivated self-confidence and reasoned action and information based communication, active participation in promoting wellbeing. Linguistic literacy is an active and dynamic phenomenon, because societies and communities are changing constantly, they are not static. People from different cultural and linguistic backgrounds, communication styles, and understanding and response to linguistic information. Enhanced linguistic literacy definitions and conceptual forms require more complex, comprehensive, socially oriented, culture sensitive, participatory linguistic education to plan more targeted education and to avoid failures in linguistic education.

The overall framework has been shown beneficial for extracting a more exact conceptual tool in understanding and developing self-confidence of students with disabilities in an English class. The empirical material has been instrumental in the development of the conceptual tool, and in the connection of methodological theories. All the aspects of self-confidence in linguistic literacy of students with disabilities interact and influence each other, but inclusion looks a little different in the practices and this might influence the understanding and development of inclusive linguistic in college education.

\section{References}

1. J. Viljaranta, A. Tolvanen, K. Aunola, J. Nurmi, Journal of Educational Research 58(6), 734-756 (2014)

2. P. Aspers, Etnografiska metoder: att förstå och förklara samtiden (1. uppl. ed. Malmö: Liber. 2007) 
3. T. Mujtaba, M. J. Reiss, International Journal of Science and Mathematics Education 12(2), 371-393. (2014)

4. S. Makoni, TESOL Quarterly 39(4), 716-719. (2005)

5. A. Tripp, T. Rizzo, Adapted Physical Activity Quarterly, 23, 310-326. (2006)

6. E. Gonida, A. Leondari, International Journal of Educational Research 50(4), 209-220. (2011)

7. M. Sapon-Shevin, Because we can change the world: A practical guide to building cooperative, inclusive classroom communities. (Needham Heights, MA: Allyn \& Bacon. 1999)

8. Susanti, Pentingnya Literasi Keuangan Bagi Generasi Muda di Surabaya, ASEAN Economic Community 2015"' Surabaya, 3 Mei, 278. (2014)

9. S. Kvale, Interviews: an introduction to qualitative research interviewing (Thousand Oaks: SAGE, 1996)

10. I. Widayati, ASSET: Jurnal Akuntansi dan Pendidikan 1(1) (2012)

11. W. Spady, Outcome-based Education: Critical Issues and Answers. (1994)

12. T. Wedege, Nordic Studies in Mathematics Education 15(1), 59-78 (2010)

13. R. Sheldrake, T.Mujtaba, M. J. Reiss, British Educational Research Journal 41(3), 462-488 (2015)

14. A. Lowell, D.Schmitt, W. Ah Chin, C. Connors, Department of Health Library Services. (2014) 